microscopical and embryological investigations. To this laboratory is added a complete aquarium, in which it is hoped to be able to keep all sorts of marine and freshwater creatures. (5) The private laboratory is organised so as to afford opportunities for every kind of physiological inquiry, so that future professors will feel at home in it, whatever may be their peculiar branch of physiological research. Then, of course, there are dark

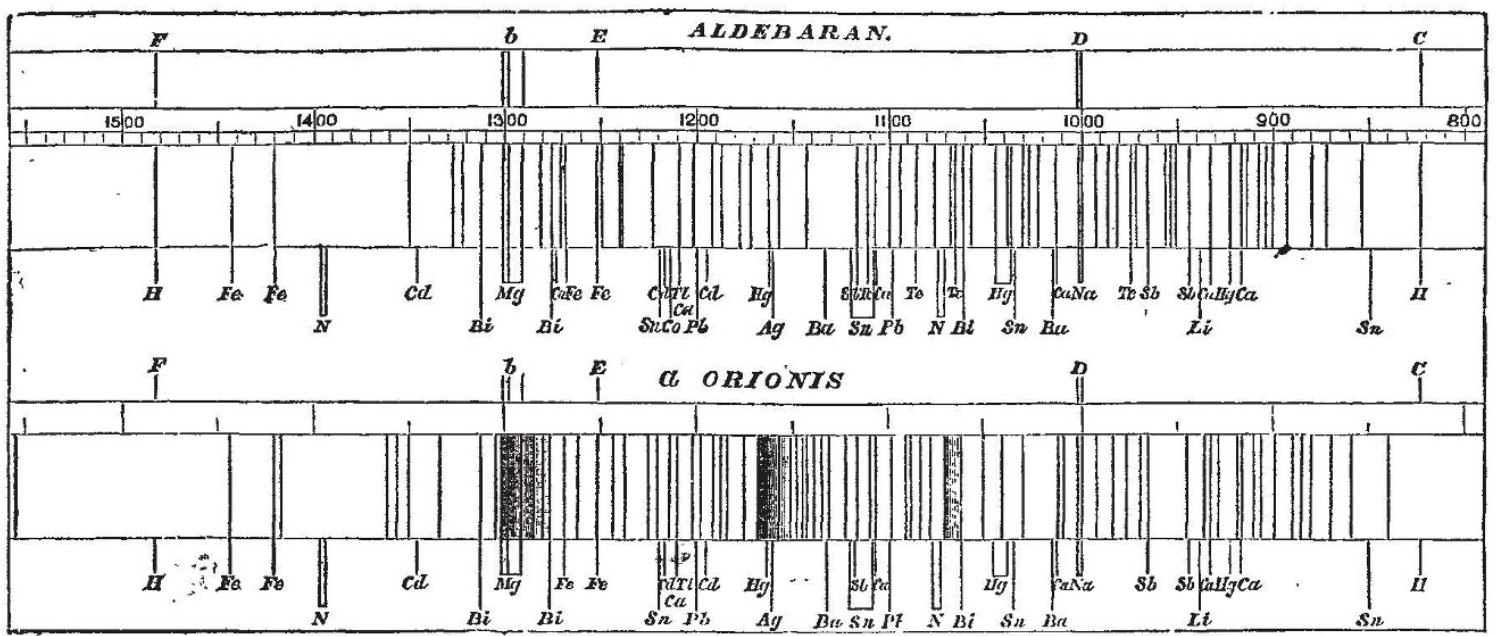

FIG. 34-.Spectra of Aldebaran and ${ }_{a}$ Orionis. (Huggins and Miller.)

chambers looking to the south for optical experiments, rooms for a respiration apparatus, and all sorts of stables, an aviary, a ranarium for the summer, and one for the winter, \&c. There is to be a dwelling-house close by, in fact so connected with the laboratory that from the study a lobby and a flight of stairs lead to the private laboratory. The House has been designed entirely according to the English fashion, and wonderful to say, hitherto has not yet met with serious opposition from the architects and the authorities. On the same premises there will be (I) Helmholtz's laboratory and dwelling-house; (2) a laboratory for inorganic chemistry; (3) one for pharmacology, under Leibreich. The accompanying sketch will give an idea of the whole. It covers an area of $4 \frac{1}{2}$ acres. The style of building is to be magnificent, much more so than

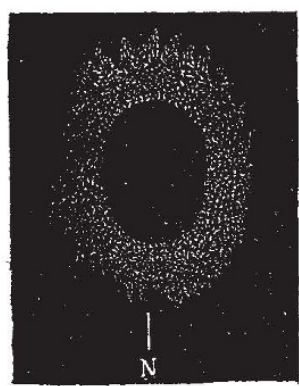

FIG. 35 .

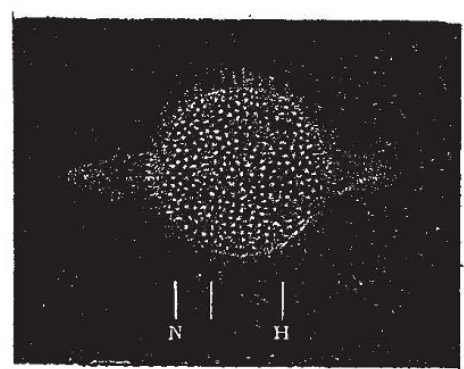

Fic. $3^{6 .}$
Fig 35.-Ring Nebula in Lyra, with its spectrum. Fig. 35.-Planetary Nebula in Aquarius, with its spectrum.

is desirable, because the costliness of the establishment increases the responsibility; but now that they are at it, they do not care for ever so many hundred thousands of dollars. All around the buildings, there will be an area, after the English plan, in order to mitigate the tremor occasioned by vehicles. In the Neue Wilhelmstrasse and the hitherto very nasty lane called Schlachtgasse there remains an open space facing the streets, so that the gardens intervening between the two great masses of building get as much light and air as is possible in the town. After all we are not so exclusively military as it may seem at a distance, and some of the French millions find their way into a scientific channel.

\section{ON THE SPECTROSCOPE AND ITS APPLICATIONS \\ VI.}

I $N$ the first place, then, what does the spectroscope tell us with regard to the radiation from the sun and the stars? And here I ask you to neglect and banish from your minds for a time any idea of those dark lines in the solar spectrum that I drew your attention to on a former occasion. I hope I shall be able to explain them satisfactorily to you afterwards, but for the present I wish you merely to take the fact that our sun, but for the dark lines, would give us a continuous spectrum. The spectrum of the stars is very much like the spectrum of the sun. In Fig. 34 is seen a representation of the spectra of two stars, $a$ Orionis and Aldebaran, mapped with the minutest care by Dr. Miller and Mr. Huggins.

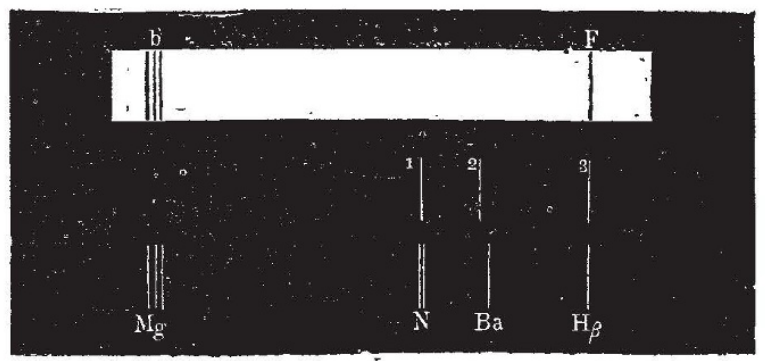

Fig. 37--Spectrum of the Nebula.- - , 2, 3, lines observed. Above, the solar specirum is shown from $b$ to $v$; below, the bright lines of magnesium, nitrogen, barium, and hydrogen, in the corresponding part of the spectrum.

In both cases we should have a continuous spectrum but for the presence of the dark lines. I think you will see in a moment what I am driving at. Suppose the sun or stars composed of only sodium vapour, for instance, it is clear that their light analysed by the prism would give us no great indication of a continuous spectrum, we should merely get one bright line in the orange. But neglect the dark lines for a moment : dealing merely with the continuous spectrum of the sun and star, it shows that we have a something, whether it be solid or liquid, or whether it be a dense gas or a vapour, competent to give us a continuous spectrum. So we are justified in assuming that sunlight and starlight proceed from the incandescence of 
a solid, a liquid or a dense gas or vapour. Again, suppose that instead of looking at the sun or the stars we observe the moon, as Fraünhofer did, as has been lbefore stated, what will happen? We get a second edition of sunlight, in exactly the same way as we should get a second edition of the sunlight in the case of a reflection of it from a mirror; and therefore, if proof of such a thing were needed, the spectroscope is perfectly competent to show us that the moon gives us sunlight second-hand. The same in the main with Jupiter, Venus, Mars, and the other planets. If we study them and observe the dark lines we find that the lines which we observe are generally the same as those which we find in the spectrum of the sun. There are other points to which I shall have to draw your attention on a future occasion, but on the whole, the teaching of the spectroscope is, that all those planets are lit up by sunlight as we know them to be.

But we have not yet exhausted the wonders of the celestial field; we have dealt merely with the sun and moon, the stars and planets. What about the nebulæ, those strange weird things, dimly shining in the depths of space, both to the eye and in the telescope obviously

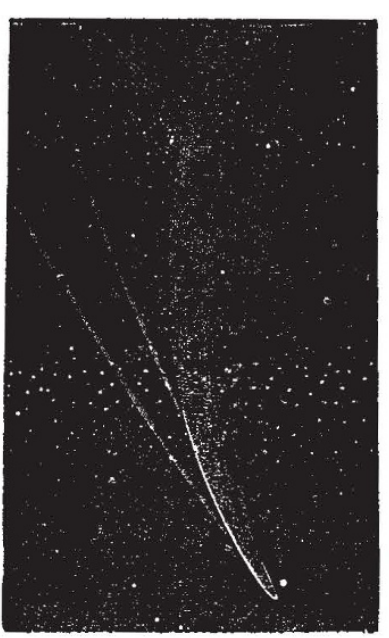

General view.

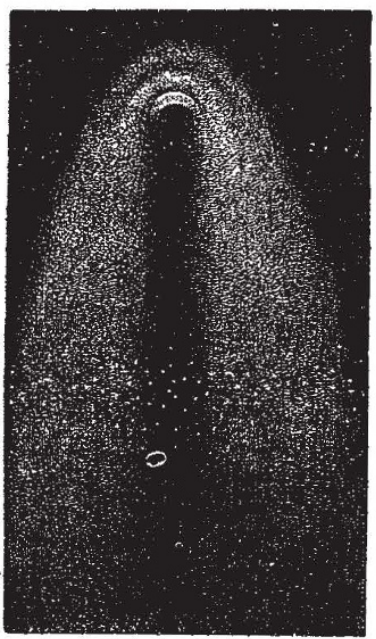

Head and envelopes
F.G 38.-Views of Donati's Comet.

and distinctly different from anything in the shape of the sun or stars? The appearance of these peculiar bodies is sufficient to show us that we have here something very different from the sun or moon. What is it? You all know as well as I do that ever since nebulæ were discovered mankind have wondered at them, and wanted to know what they were ; and you are also aware that it was not settled and could not be settled before the advent of the spectroscope, but that it could be settled in five minutes after that event. Mr. Huggins, who first observed the spectrum of a nebula, found that, instead of the continuous spectrum with which you are familiar in the case of the sun and the stars-always asking you to neglect the Frainhofer lines, which I shall explain afterwards-the light which he got from the nebula consisted merely of three lines. He was exceedingly astonished, so much so that he thought the instrument might be out of order. However, it became perfectly clear to him in a very short time that there was no mistake at all, and that all that the light which came from the nebula could do was to give him these three faint lines. No doubt you have anticipated my explanation. The nebulæ are composed of tenuous gases or vapours. After what I have said about the way in which the spectroscope at once picks out the difference between a solid or liquid, and a vaporous or a gaseous body, you will see at once that these three bright lines indicate that the nebulæ, instead of being composed of solid, liquid, or densely gaseous bodies-instead of being like the sun or stars-are really composed of rare gases or vapours. Mr. Huggins was enabled, in fact, to determine the gas in one instance, for one of the lines he found was coincident with one of the principal lines in the spectrum of hydrogen one of the other lines possibly being due to nitrogen. And now comes another extremely important point, showing the importance of studying the most minute changes in gaseous spectra, for Mr. Huggins, who knew the spectrum of hydrogen and the spectrum of nitrogen well, and who knew how extremely complicated those spectra are at times, was much astonished at finding only one line of hydrogen and one of nitrogen, and attempted to account for the singleness of the lines, first, by assuming a condition of the gas different from anything
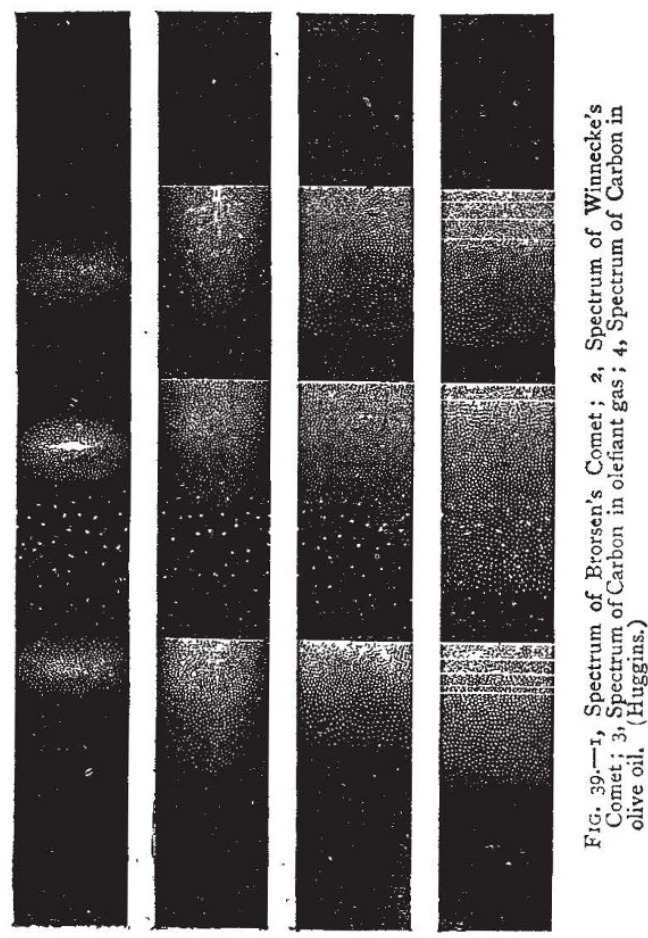

we meet with a our laboratories, and again by assuming an absorbing medium in space. But after Dr. Frankland and myself had made some observations on the spectra of hydrogen and nitrogen, we found it was perfectly easy to obtain, and sometimes when one did not want it, a spectrum of hydrogen or of nitrogen giving only one line; or nearly so ; so that by comparing the conditions which were necessary to obtain these conditions in our tubes with the conditions of the nebulæ, it was quite possible to make at all events a rough guess at what is the constitution of the nebulæ, so far as pressure or molecular separation goes. We find, for instance, this single line of hydrogen, and a nearly single line of nitrogen, when the pressure is so slight that you would say that the tube really contained nothing at all, and when, moreover, the temperature is comparatively low. Now, not only is this a fact, which we are quite prepared to assert, merely on the evidence rendered us by these tubes, but $I$ think you will acknowledge that it is entirely in accordance with everything we know astronomically on this subject.

For the next application of the spectroscope in this direction, let us take a comet. The appearance of a 
comet is probably well known to many, who will recollect the form of Donati's comet. Although, as you know, that comet appeared only about ten years ago, unfortunately it came too early for us to learn anything about it by means of the spectroscope. We have, first of all, an extremely bright nucleus; then a kind of semilune of greater brilliancy than the rest of the head; then what is called the coma, and the tail. The question which the spectroscope had to put to the comet was-of what is the nucleus composed, and of what is the tail composed. Prof. Donati, and Mr. Huggins especially, to whom we owe so much fur his work in this direction, has made some observations on two small comets-I am sorry they were not larger-with considerable success. He found that in the comets he examined, the head gave out a light which very strongly indeed resembled the spectrum of carbon vapour. The spectrum of carbon taken with the spark in olive oil and in olefiant gas differs slightly; the spectrum as obtained from the latter consists of three bands or waves of light, which commence tolerably bright and sharply on the red side, and become gradually fainter towards the more refrangible side. These bands are severally situated in the beginning of the green, in the true green, and in the blue portions of the spectrum. Mr. Huggins has also observed the spectrum of Encke's comet, and has confirmed the result that he previously obtained, viz., that the spectrum of the comet is identical with the spectrum of carbon, as taken in a hydrocarbon. I should like to draw your attention, if there were time, to the way in which these spectra of the carbon spark taken in oil and in olefiant gas, differ.

I have not yet completed all I have to say on the subject of radiation. If, as we have already seen, we take a tube containing incandescent hydrogen and pass a series of intense electric sparks through it, we see that it gives out a red light, which may remind you of some otlier specimens of radiation which is supplied us by the skies. I allude to the red prominences which are seen around the sun, not in ordinary times, but when the sur. is eclipsed. This representation gives you a good idea of what really is seen when the sun is eclipsed, when we have as it were a black sun instead of a bright one, which is really nothing, but the body of the moon. Around this we have a ring of light, which is called the corona, and here and there in this corona we have what are called red flames and red prominences. These red prominences have also on closer observation been found to be only local aggregations or heapings up of a red layer which surrounds the outer edge of the sun. Here, then, it was quite possible that if the newly invented spectroscope were set to question these things, we should see at once whether they were solid or liquid, or whether they were gaseous or vaporous. If we got a continuous spectrum from these red things, we should know that they were solid, or liquid, or densely gaseous. If, on the contrary, we got a bright line spectrum we should know we were dealing with a gas or vapour. You also see that, as the light is red, the chances were that they were not solid or liquid, and then you further see that if the things do consist of a light which does give us lines, a determination of the exact position of the lines, and a comparison of these positions with those of hydrogen, sodıum, magnesium, barium, or anything else, would teach us what these things were.

J. NORMAN LOCKYER

\section{PROF. FLOWER'S HUNTERIAN LECTURES} LECTURES XIII. XIV. XV.

$T A P I R I D A E$. The geographicaldistribution of the existing members of this small order is very peculiar, they being confined to the Malay Peninsula, Sumatra, and most of South America. Lund has found their remains in the Post-pleistocene caves of Brazil ; they have also been obtained in abundance from similar deposits in North America, and these can hardly be distinguished from those at present existing ; in China likewise Pleistocene Tapir's teeth have been found. In Europe during the same time they do not seem to have existed, although Elephants and Rhinoceroses were abundant. In the Pliocene and Miocene, Tapirs are not unfrequently met with at Eppelsheim, Auvergne, and elsewhere ; perhaps they originated in Europe, and thence spread east into Asia, and on to America. Respecting their anatomical peculiarities, the teeth are forty-two in number, the anterior lower premolar being absent; the molars and premolars are much alike, forming a uniform series; the incisors are smaller than the canines, they have a small cingulum. The molars are a modification of those of Lophiodon, the transverse ridges are very prominent, and the cusp of the cingulum is less developed. The lower possess two simple transverse ridges, as in Lophiodon, but the last in the series wants the extra back lobe. The anterior nares are very open and the orbit is incomplete behind. There are four toes on the front foot, and three behind; the radius and ulna as well. as the tibia and fibia are quite separate and well developed ; $T$. bairdi is peculiar in that the mesethmoid cartilage is well ossified, and the maxillaries are specially developed upwards to support it.

The Palceotheridee occur in the Upper Eocene only, they were first found at Montmartre and worked out by Cuvier; since that time they have been obtained from many parts of France, the Bembridge clay, near Yarmouth, in the Isle of Wight, and in Hampshire. Several genera have been separated off, and about a dozen species, from the size of a small rhinoceros downwards. In general aspect they must have been tapir-like. The maxilla curved downwards in front as in the tapirs; the orbital and temporal fossæ were also united, and there were large anterior osseous nares; the feet were much like those of the tapir, though they were more specialised in wanting the fifth toe to the manus. The typical fortyiour teeth were present ; the incisors were more uniform than in the tapirs; the first pre-molar was rather rudimentary, the others formed a uniform series with the molars, which were wider than from before backwards, much pressed together, and with short crowns. They can be shown to have been developed on the type of Lophiodon, the outer wall bulging inwards, opposite the outer cusps, instead of outwards, giving the earliest indication of the lunate type of tooth; the transverse ridges were normal, and the internal cusps were slightly cut off from them, turning backwards as the rudiments of the posterior semilunes. The lower teeth presented a peculiarity here first noticed, each being formed by a double crescent, quite different from those of the tapir. The last lower molar had a third crescent behind as in Lophiodon and the Artiodactylata, but, different from the latter, in the corresponding milk tooth not presenting it. Palaplotherium was a smaller and earlier genus described by Owen from Hordle. In the upper jaw the first premolar was missing, and the corresponding lower one soon lost; the others were comparatively simple. The remains are very abundant, the feet were as in Palæotherium. Gervais has given the name Propalaotherium to a few teeth of another early form, intermediate between Lophiodon and Palæotherium. Anchitherium was an American form closely allied to the strictly European Palæotheridæ.

Rhinocerotida are at present found in Africa and South Asia only; they belong to three types, the African two: horned, non-scutellated ; the Asiatic two-horned, and the Asiatic single-horned. The extinct members were numerous; four species existed in England. They did not appear before the Miocene epoch; many are found in America, but not above the Pliocene period. The existing genera have peculiarities in their incisor dentition; these teeth are quite absent in the African, and two above as well as below in the Indian species; when they are 